American Journal of Pharmaceutical Education 2019; 83 (5) Article 6784.

\title{
RESEARCH
}

\section{Pharmacy Students' Reflections on an Experiential Learning Visit to a Psychiatric Hospital}

\author{
Dolores Keating, MSc, ${ }^{\text {a,b }}$ Stephen McWilliams, MMEd, MD, ${ }^{\mathrm{a}}$ Caroline Hynes, MSc, ${ }^{\mathrm{a}, \mathrm{b}}$ Mary Clarke, MD, \\ Judith Strawbridge, MSc, $\mathrm{PhD}^{\mathrm{b}}$ \\ ${ }^{a}$ Pharmacy Department, Saint John of God Hospital, Stillorgan, Co Dublin, Ireland \\ ${ }^{\mathrm{b}}$ School of Pharmacy, Royal College of Surgeons in Ireland, 123 St Stephen's Green, Dublin, Ireland \\ ${ }^{c}$ DETECT Early Intervention in Psychosis Service, Blackrock, Co Dublin, Ireland \\ ${ }^{\mathrm{d}}$ School of Medicine, University College Dublin, Dublin, Ireland \\ Submitted September 10, 2017; accepted October 17, 2018; published June 2019.
}

\begin{abstract}
Objective. To create a brief, experiential educational intervention for undergraduate pharmacy students aimed at developing appropriate attitudes, knowledge, and skills for the delivery of recoveryfocused pharmacy services to people with mental illness, and to elicit student perceptions of the value and impact of the intervention.

Methods. A brief intervention was developed in which a cohort of 44 fourth-year pharmacy students attended a psychiatric teaching hospital in groups of 10 to12. The intervention was integrated into the therapeutics module, and was based on Fink's taxonomy of learning. Delivery of the intervention included input from a multidisciplinary team of mental health professionals and the use of activelearning strategies to give students an insight into the holistic approach to care and the patient journey. Students participated in an exercise in reflective practice following the visit. Content analysis was performed on the reflective writings of consenting students to identify themes and insights gained.

Results. Thirty-eight of the 44 students gave their consent for their reflective writings to be analyzed for the purpose of this research. Students expressed some apprehension before their visit to the hospital, but later gained an appreciation of the patient experience of care in the psychiatric setting. Students also described having a greater appreciation of the role of the pharmacist in caring for psychiatric patients as well as an insight into the role of other health care professionals and interventions supporting recovery. Conclusion. A brief experiential intervention helped students integrate their learning and appreciate the value of their expertise in supporting those experiencing mental illness.
\end{abstract}

Keywords: pharmacy, education, mental health, psychiatry, teaching

\section{INTRODUCTION}

As frontline health care providers, pharmacists have frequent contact with people who have mental health problems and provide important services aimed at optimizing the use of psychotropic medication. ${ }^{1,2}$ Mental health conditions are highly prevalent in the community setting with approximately one in five people developing a diagnosable condition each year. ${ }^{3}$ The lifetime prevalence of mental illness in developed countries is estimated at $50 \%$. $^{3,4}$ Therefore, pharmacy graduates having the appropriate attitudes, knowledge, and skills to deliver mental health services is vital. However, the training provided

Corresponding Author: Dolores Keating, Pharmacy Department, Saint John of God Hospital Stillorgan, Co Dublin, Ireland and School of Pharmacy, Royal College of Surgeons in Ireland, 123 St Stephen's Green, Dublin 2. Tel +35312771607. E-mail: Dolores.keating@sjog.ie to pharmacists at the undergraduate level is highly variable with regard to the teaching methods used, time dedicated to mental health education, expertise of the lecturers, and topics covered. ${ }^{5-7}$ Experiential placements for undergraduate pharmacy students in mental health settings are limited, and there are few opportunities for interprofessional education or contact-based learning where students meet people who have experienced mental health difficulties. ${ }^{5-8}$ Consequently, pharmacists feel poorly prepared to manage medication-related issues, communicate effectively, or understand the different approaches to mental health care beyond the use of medication. $5,9,10$

The recovery approach is central to the delivery of a modern mental health service. ${ }^{11}$ A widely used definition of recovery is from the work of Anthony who asserts, "Recovery is a deeply personal, unique process of changing one's attitudes, feelings and goals, skills and/or roles. 


\section{American Journal of Pharmaceutical Education 2019; 83 (5) Article 6784.}

It is a way of living a satisfying, hopeful and contributing life even within the limits caused by illness. Recovery involves the development of new meanings and purpose in one's life as one grows beyond the catastrophic effects of mental illness." 12 Introducing this concept of recovery to undergraduate pharmacy students is important because it has implications for the way medication use is approached in mental health care. ${ }^{13}$ Users of mental health services recognize that medication can both support and interfere with personal recovery and feel they need to be partners in their own care, making informed choices, having their concerns listened to, and their choices respected. ${ }^{13,14}$ Contact-based learning and describing personal recovery stories are examples of recovery-focused teaching methods that have been demonstrated to improve student attitudes towards those experiencing mental illness and make students more hopeful for positive patient outcomes. ${ }^{8,14,15}$

Undergraduate curricula must be designed to fulfil the expectations of the pharmacy profession as described in the Pharmaceutical Society of Ireland's Core Competency Framework for the domains of professional practice, personal skills, and public health. ${ }^{16}$ For example, pharmacists must demonstrate a "patient-centred approach to care,"; "treat others with sensitivity, empathy, respect and dignity"; and recognize the value and structure of a multi-professional team. Fink's Taxonomy of Significant Learning describes an integrated approach whereby each kind of learning can stimulate other kinds of learning. ${ }^{17}$ This taxonomy is described in the domains of foundational knowledge, application, integration, human dimension, caring, and learning how to learn. Although largely unexplored in pharmacy education research relating to mental health, the use of Fink's approach to course development could prove important in an area of health care where the attitudes of clinicians and human factors such as stigma can have an important impact on patient outcomes. ${ }^{18-20}$

This project began in 2013 when an innovative collaboration between a school of pharmacy and an acute psychiatric teaching hospital was initiated. While specialist teaching from practicing clinicians and practice-based work experience were components of the agreement, there was a wider vision of providing students with a broad knowledge about mental health care that would support pharmacy practice in all settings. This collaboration was supported by the management team and the clinical leadership of the hospital which facilitated input from a variety of mental health professionals and service users. The aim of this study was to create a brief experientiallearning intervention at a psychiatric hospital and evaluate its impact through the analysis of student reflections.
Ultimately, we hoped that the training and education provided to students would give them the skills and confidence to engage effectively in mental health care and begin to address pragmatically some of the gaps described in the literature around mental health education for pharmacists.

\section{METHODS}

This educational intervention was part of a longitudinal, mixed methods study aimed at exploring the impact of the undergraduate pharmacy program on students' attitudes towards mental illness and confidence in providing mental health care. Additional educational activities included epidemiology, pathophysiology, and pharmacotherapy of mental illnesses; practice-informed didactic lectures on the therapeutic use of psychiatric medication delivered by specialist mental health pharmacists; training in mental health first aid; engaging patients in curriculum review; and patient contact sessions during which patients discussed their recovery journey with students. Ethics approval was received from the Research Ethics Committee at the Royal College of Surgeons in Ireland (RCSI).

Our hypothesis was that the learning environment of the psychiatric hospital setting combined with the content of the brief experiential educational intervention would support positive attitudes among students towards the provision of pharmacy services for those experiencing mental illness and promote a holistic understanding of mental health services. Participants were students in their fourth year of pharmacy education at the RCSI. Students were required to participate in one experiential learning visit at the affiliated psychiatric teaching hospital as part of the therapeutics module. Students visited the hospital in groups of 10 to 12 over a four-week period in fall 2014. The visits lasted approximately four hours.

The content of the experiential educational intervention was developed by practicing mental health pharmacists and the school of pharmacy in collaboration with members of the multidisciplinary team at the psychiatric hospital. The learning goals were developed following a review of the relevant literature and the current curriculum with reference to Fink's taxonomy of learning (Table 1). ${ }^{21}$ The aim was to provide students with an overview of mental health care and how the pharmacist supports people who use mental health services.

The components of the experiential learning visit and the format of delivery are described in Table 2. Studentfocused, active-learning strategies were used. Active learning allows students to retain what they learn longer because they are active participants in the course rather than passive learners. ${ }^{22}$ Opportunities for active learning 


\section{American Journal of Pharmaceutical Education 2019; 83 (5) Article 6784.}

Table 1. Learning Goals for an Experiential Learning Visit for Undergraduate Pharmacy Students to a Psychiatric Teaching Hospital as Mapped to Fink's Taxonomy of Learning and the Core Competency Framework of the Pharmaceutical Society of Ireland

\begin{tabular}{|c|c|c|}
\hline Learning Goals & Fink's Taxonomy & PSI Core Competency \\
\hline $\begin{array}{l}\text { Develop more understanding into the patient experience in } \\
\text { a psychiatric hospital. }\end{array}$ & $\begin{array}{l}\text { Integration, caring, human } \\
\text { dimensions }\end{array}$ & 1.1.1, 1.1.4, 1.2.3, 2.3.4, 2.3.5 \\
\hline $\begin{array}{l}\text { Appreciate the roles and inputs to patient care of various } \\
\text { members of the multidisciplinary team and how a } \\
\text { pharmacist interacts with the team. }\end{array}$ & $\begin{array}{l}\text { Foundation knowledge, } \\
\text { integration, human } \\
\text { dimensions }\end{array}$ & $2.3 .1,2.3 .4,2.3 .4,2.3 .5$ \\
\hline $\begin{array}{l}\text { Be more interested in a recovery-based approach to mental } \\
\text { health care and the role of medication. }\end{array}$ & $\begin{array}{l}\text { Integration, caring and } \\
\text { human dimension }\end{array}$ & $1.2 .3,5.1 .1$ \\
\hline $\begin{array}{l}\text { Reflect on and value the role of the pharmacist in promoting } \\
\text { mental health and wellbeing. }\end{array}$ & $\begin{array}{l}\text { Knowledge, caring, } \\
\text { human dimension }\end{array}$ & $\begin{array}{l}\text { 1.1.1, 1.1.3, 1.1.4, 1.2.3 } \\
\quad 5.1 .1,5.2 .1,5.2 .2,5.2 .3\end{array}$ \\
\hline
\end{tabular}

within the program included: observation, stories, case studies, participation, reflective thinking, and dialogue. For example, students participated in a simulated psychology group facilitated by a clinical psychologist. While the pharmacists used case studies to explain their contribution to person-centred care, they also shared stories from their personal experience such as "the first person I felt I helped." Facilitation techniques were used to encourage open discussion. Patients were not asked to interact directly with students, but they were present in the patient care areas where students visited. The recovery approach underpins all care provision at the hospital, making this concept a building block for all interactions with patients.

Having the acute psychiatric hospital as the setting for the educational intervention was a key element. The hospital serves the needs of the public sector within the geographical catchment area and private patients who have health insurance. Thus, every demographic category is represented in the inpatient cohort. In addition to general adult psychiatry, specialist services are provided in the areas of addiction, eating disorders, psychiatry of later life, and adolescent mental health. Patients avail themselves of clinical interventions and recreational activities at locations across the campus.

We chose qualitative methodology to gain an understanding of students' perceptions of the experiential learning visit and insight into how the learning objectives were being met. As part of the standard assessment process, students were required to complete and submit an exercise in reflective practice. Reflective practice is a technique used both in undergraduate education and continuing education for health care professionals. ${ }^{23} \mathrm{Re}-$ flective practice exercises encourage the student to draw and learn from their own experiences and the experiences of others, thus helping to guide their future practice and approach to care.
The students completed the exercises in reflective practice two months after all of the students had attended the experiential learning visit. Students were encouraged to reflect on the insights they gained into mental-health care during their visit to the hospital and whether this experience would be of benefit to them in their future careers. The timing of the reflective practice exercise was chosen to coincide with the completion of the therapeutics module. This facilitated follow-up evaluation rather than immediate post-intervention evaluation. The module coordinator acted as a gatekeeper, ensuring that identifying information was removed from the reflective writings before they were made available for analysis. Consent was requested from students to use the anonymized reflective writings for the purpose of evaluating the experience. A small number of grade points were awarded for student engagement, including for attendance and submission of the exercise in reflective practice. The content of the reflective writings was not graded.

Thematic content analysis was performed on the reflective writings to identify themes that were relevant to the research question. The approach was deductive and based on our hypothesis that the students would gain relevant insights into mental health care as described in the learning goals. The data were analyzed independently by two of the researchers (DK and $\mathrm{CH}$ ) to identify anticipated and emergent themes. Key phrases and comments that exemplified themes were identified and coded independently. The results were then discussed until consensus was reached, allowing the researchers to converge the data into overall themes and develop the results.

\section{RESULTS}

Thirty-eight students gave consent for their reflective writings to be analyzed for the purpose of evaluating the experiential learning visit to the psychiatric hospital. The themes listed in Table 3 were identified from the data. 
American Journal of Pharmaceutical Education 2019; 83 (5) Article 6784.

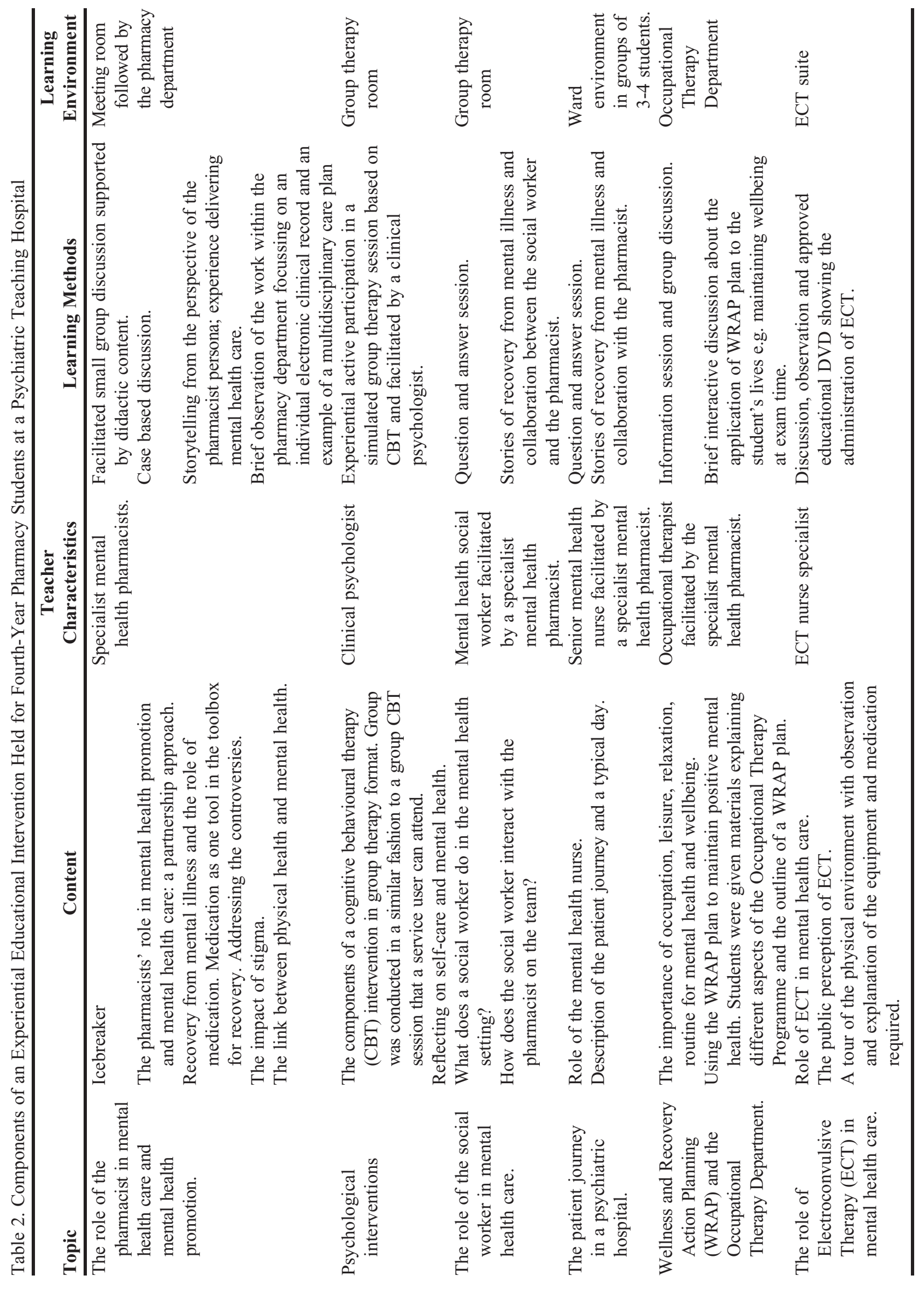




\section{American Journal of Pharmaceutical Education 2019; 83 (5) Article 6784.}

Table 3. Themes Identified from Qualitative Analysis of Pharmacy Student Reflections Following an Experiential Learning Visit to a Psychiatric Teaching Hospital

1. Initial Apprehension

2. Multidisciplinary Working

3. Understanding the Patient Experience

4. The Role of Electroconvulsive Therapy

5. Engaging with People who are Experiencing Mental Health Difficulties

6. Recovery

The themes that emerged were congruent with the learning goals (Table 1).

The initial theme to emerge from the data was that almost half of the students expressed apprehension about the visit (Appendix 1). One reason for this apprehension was a lack of knowledge about the environment of a psychiatric hospital. The physical aspect of the learning environment was therefore important in achieving the learning goals (Appendix 1). A second reason for the initial apprehension about the visit was that that the fourth-year students found the prospect of providing mental-health care daunting (Appendix 1). They had yet to begin formal practice-based learning, and this apprehension may have simply reflected a lack of experience. Four students described previous contact with people experiencing mental illness, which may have reduced their apprehension about the visit (Appendix 1).

An appreciation for working in multidisciplinary teams was demonstrated in the content of the exercises in reflective writings. The majority of students felt that they benefitted from their interaction with other health care professionals (Appendix 1). The students were positive about the experiential nature of the visit and felt that it helped them understand the patient experience (Appendix 1). While the use of electroconvulsive therapy (ECT) had not been a specific learning goal, its inclusion in the site visit gave students the opportunity to reflect on their own attitudes toward ECT and voice questions or concerns they had about the treatment (Appendix 1).

The key theme of the reflections with regard to future pharmacy practice was engagement, and this was in accordance with the learning goal of valuing the role of the pharmacist in mental health care. The students felt that their experience at the hospital made them aware of the need to speak to people who are taking medications for mental health difficulties, to ask how they are tolerating the medications, and to give the same level of pharmaceutical care to those with mental illness as to those with physical illness (Appendix 1). Input from the social work and occupational therapy departments allowed the stu- dents to develop a more complete picture of the personal journey along a spectrum of mental health and wellbeing rather than focusing entirely on the acute phase of mental illness. The students showed some insight into recoveryfocused care following their participation in the program (Appendix 1).

\section{DISCUSSION}

This study aimed to understand how a brief experiential learning opportunity in a specialist mental health setting would be viewed by pharmacy students through the use of reflective practice. Content analysis of the reflective writings showed congruency with the learning goals. The results indicated that students gained a better insight into a holistic approach to care, the patient experience, the concept of recovery, and the importance of engaging with people who are experiencing mental health difficulties.

Medication use in mental health care is often suboptimal because patients can experience disabling side effects and adherence to medication is often poor. ${ }^{24-29}$ Pharmacists' involvement in care can help improve outcomes for those who live with mental health conditions by improving the quality of prescribing practice, conducting medication use reviews, encouraging patients to adhere to medication, providing individualized medicines information, and supporting shared decision making. ${ }^{30-33}$ Community pharmacists actively engage in mental health promotion. Emerging mental health problems or worsening of existing mental health difficulties can be detected in the pharmacy setting, allowing appropriate signposting and early intervention. ${ }^{1,2}$ Despite this, studies exploring pharmacists' attitudes towards providing mental health care show that while they are willing to engage with people with mental health conditions, there is a lack of confidence in doing so compared to their confidence in providing physical health services. ${ }^{10,32,34}$ The students' reflections about the intervention indicated an improved perception of the value of pharmacists in supporting people with mental health difficulties.

While the move away from institutionalized care in mental health services to a community-oriented approach has been happening for many years, negative attitudes and perceptions about people with mental illness and psychiatric care are slow to change among the general population, and this may have led to the apprehension described in the student reflections. ${ }^{35,36}$ We offered students the opportunity to have contact with people receiving care in the psychiatric hospital setting and to learn about their daily activities and the interventions provided to them. Multidisciplinary teams deliver a holistic service as recovery in mental health care is no longer focused entirely 


\section{American Journal of Pharmaceutical Education 2019; 83 (5) Article 6784.}

on symptom reduction, but also encompasses the person's social and occupational goals. ${ }^{12,37}$ Pharmacists are accessible health care professionals, available to support people in accessing many types of effective interventions that can improve their health and wellbeing. ${ }^{1,2}$ In order to do this effectively, the pharmacist needs to be aware of the impact of mental health stigma, have a good knowledge of the mental health services available to patients, and understand how other health care professionals contribute to an individual's recovery journey.

For example, ECT is a treatment option offered to people experiencing severe treatment-resistant depression or mania, and occasionally other severe psychiatric difficulties. ${ }^{38}$ It is a controversial treatment despite its proven efficacy, and there is significant stigma associated with its use. ${ }^{39}$ Despite the inclusion of ECT in the content of lectures, the pharmacy students who visited the hospital did not seem to be aware that ECT was still used or what it meant in practice for the person receiving the treatment. The experiential nature of the students' visit to the ECT suite, where they observed the environment and viewed a DVD that showed the administration of the treatment, supported the lecture content.

Recovery from mental illness does not necessarily mean the patient is "cured" (or in clinical recovery). Instead it emphasizes the unique journey of an individual living with mental health problems to build a life for themselves beyond illness (in other words, "social recovery"). ${ }^{12,40}$ Slade argues that medication should be viewed as an "exchangeable protection against relapse," whereby pharmacological and psychosocial approaches are used together to "buffer the individual against relapse." 37 Medication can be conceptualized as one tool that a person may choose to use to maintain wellbeing or to support their own personal recovery. ${ }^{41,42}$ Importantly, pharmacists should approach interactions with people who are experiencing mental health difficulties with an attitude of hope with the aim of empowering the person to take a proactive role in their own care. ${ }^{13}$ A core aspect of medicines optimization is that pharmacists and other health care providers aim to understand the person's experience of using medicines in order to support them in achieving the best outcomes from their medication. ${ }^{43}$ A pharmacist having the ability to see situations from the patient's perspective and empathize with them will support the development of a good therapeutic relationship. ${ }^{44}$ In a recovery-focused approach to mental health care, this understanding of the person's experience must extend beyond the use of medication.

Educational interventions that improve students' attitudes toward mental health are hypothesized to improve their professional ability to engage effectively with people who have a mental illness. ${ }^{19,45}$ The educational interventions for pharmacists described in the literature involved pharmacists attending lectures and workshops in which the role of the pharmacist in mental health was explained, patient experiences of living with mental illness were described, case studies were studied, discussions about stigma were held, and mental health first-aid training in addition to the pharmacology and therapeutics of psychotropic medication were taught. ${ }^{46-50}$ More indepth educational interventions are frequently offered to pharmacy students as optional modules, with students self-selecting into the programs. ${ }^{6,44,49}$ Social-contactbased interventions among students improve attitudes towards those with mental illness, at least in the short term. ${ }^{36}$ Interprofessional education is increasingly recognized as having the potential to facilitate a more integrated approach to health care provision in the future. Mental health professionals in Ireland have very few opportunities for interprofessional learning or contact at the undergraduate level. ${ }^{51}$ Our study demonstrates the value of multidisciplinary input into undergraduate pharmacist education by showcasing how various professionals work together in the mental health setting, an outcome which would be enhanced further through interprofessional learning.

Involving specialist mental health pharmacists and members of the multidisciplinary team in course design was a key factor to success. According to Fink's taxonomy, reflecting about oneself and others informs students about the human significance of what they are learning. ${ }^{17}$ Also, when students care about something, "they have the energy they need to learn more about it and making it part of their lives." 17 Recovery-focused teaching methods give health care students a better appreciation of the issues involved in treatment and outcomes for people experiencing mental illness. ${ }^{14,15,52}$ The ability and confidence to engage with people and listen to their experience with using medicines is vital if pharmacists are to support people in achieving the best outcomes from their medicines. $^{43}$ The school of pharmacy hopes that by the end of students' undergraduate training in pharmacy the mental health teaching provided will inspire in them an interest in the topic, encourage them to engage empathetically with people who have mental health problems, and change how they view their own health and well-being and that of others.

Thematic content analysis allowed us to examine the perspectives of the students about the experiential learning visit, explore how the learning goals were met, and elicit some unanticipated insights. Two researchers analyzed the data to reduce the risk of bias. While it was not 


\section{American Journal of Pharmaceutical Education 2019; 83 (5) Article 6784.}

possible to ensure that all groups had an identical experience, the components remained consistent. All students had equivalent learning opportunities throughout the module, albeit delivered at varying times over a fourweek period. The student were asked to reflect specifically on the site visit, but external factors, eg, patient contact sessions, may have influenced their thinking. The experiential learning visits were facilitated by the chief pharmacist of the hospital, who is also an honorary senior lecturer in the school of pharmacy. This may have influenced the content of the reflections if the students felt obliged to state what they believed the senior lecturer wanted to hear. However, the facilitator had no role in student assessment, the gatekeeper who gathered the reflective writings was not part of the research team, and the reflections were written two months after the end of the module, during which time the students had no further contact with the facilitator. The influence of an enthusiastic teacher in improving students' attitudes towards mental illness has been shown not to be as powerful as the students themselves gaining an understanding of the patient's perspective of mental-health care. ${ }^{8}$

A strength of this study was the multidisciplinary collaboration facilitated by a formal memorandum of understanding between a school of pharmacy and a psychiatric teaching hospital. Studies evaluating the extent and quality of undergraduate pharmacy programs have recommended that more experiential training opportunities in mental health care be made available to students. ${ }^{5-7}$ This presents a practical problem because of a lack of available placements in community or inpatient mental health services. The educational intervention described in this study is a pragmatic approach to understanding mental health patients and offers all undergraduate pharmacy students brief exposure to specialist mental health care. The study adds to the existing literature regarding educational interventions for pharmacists in the area of mental health care. Longitudinal follow up is needed to understand how these interventions affect the attitudes and behaviors of practicing pharmacists.

\section{CONCLUSION}

An experiential learning visit to a specialist mental health setting that offers opportunities for multidisciplinary contact and recovery-focused teaching, can have a positive impact on pharmacy students' understanding of mental health care and the personal recovery journey. Students gained a greater insight into the patient experience, the holistic approach to care, and recovery from mental illness. Their perception of the value of a pharmacist's support for people experiencing mental health difficulties improved, which we hope will give them more confidence in providing mental health care in the future. Such brief interventions could form part of a comprehensive approach to mental health education that includes communication skills and contact-based learning in addition to the traditional theory-based approaches.

\section{ACKNOWLEDGMENTS}

The authors wish to acknowledge the contribution to the development and delivery of the experiential learning programme by the mental health professionals at Saint John of God Hospital. We also acknowledge the support of the staff and management of the School of Pharmacy at the Royal College of Surgeons in Ireland and the Management Team at Saint John of God Hospital.

\section{REFERENCES}

1. Pharmaceutical Society of Australia. Mental Health Care Project. A Framework for Pharmacists as Partners in Mental Health Care. https://www.psa.org.au/wpfb-file/mental-health-framework-pdf. Accessed March 10, 2017.

2. International Pharmaceutical Federation. Focus on mental health: the contribution of the pharmacist. https://www.fip.org/www/ streamfile.php?filename=Focus_on_mental_health_-final.pdf. Accessed March 10, 2017

3. Cannon M, Coughlan H, Clarke M, Harley M, Kelleher I. The Mental Health of Young People in Ireland: A Report of the Psychiatric Epidemology Research across the Lifespan (PERL) Group. Royal College of Surgeons in Ireland. https://epubs.rcsi.ie/ cgi $/$ viewcontent.cgi?article $=1000 \&$ context $=$ psychrep. Accessed April 20, 2017.

4. Kessler RC, Berglund P, Demler O, Jin R, Merikangas KR, Walters EE. Lifetime prevalence and age-of-onset distributions of DSM-IV disorders in the National Comorbidity Survey Replication. Arch Gen Psychiatry. 2005;62(6):593-602.

5. Rutter P, Taylor D, Branford D. Mental health curricula at schools of pharmacy in the United Kingdom and recent graduates' readiness to practice. Am J Pharm Educ. 2013;77(7).

6. Cates ME, Monk-Tutor MR, Drummond SO. Mental health and psychiatric pharmacy instruction in US colleges and schools of pharmacy. Am J Pharm Educ. 2007;71(1):Article 4.

7. Mey A, Hattingh L, Davey AK, Knox K, Fejzic J, Wheeler AJ. Preparing community pharmacists for a role in mental health: an evaluation of accredited Australian pharmacy programs. Curr Pharn Teach Learn. 2015;7(3):371-377.

8. Patten SB, Remillard A, Phillips L, et al. Effectiveness of contactbased education for reducing mental illness-related stigma in pharmacy students. BMC Med Educ. 2012;12(1):1.

9. Cannon-Breland ML, Westrick SC, Kavookjian J, Berger BA, Shannon DM, Lorenz RA. Pharmacist self-reported antidepressant medication counseling. J Am Pharm Assoc. 2013;53(4):390-399. 10. Liekens S, Smits T, Laekeman G, Foulon V. Pharmaceutical care for people with depression: Belgian pharmacists' attitudes and perceived barriers. Int J Clin Pharm. 2012;34(3):452-459. 11. A National Framework for Recovery in Mental Health. Health Services Executive. https://www.hse.ie/eng/services/list/4/ mental-health-services/advancingrecoveryireland/national- 


\section{American Journal of Pharmaceutical Education 2019; 83 (5) Article 6784.}

framework-for-recovery-in-mental-health/. Accessed November 20, 2017.

12. Anthony WA. Recovery from mental illness: The guiding vision of the mental health service system in the 1990s. Psychosoc Rehab J. 1993;16(4):11.

13. Baker E, Fee J, Bovingdon L, et al. From taking to using medication: recovery-focused prescribing and medicines management. Adv Psychiatr Treat. 2013;19(1):2-10.

14. Feeney L, Jordan I, McCarron P. Teaching recovery to medical students. PsychiatrRehabil J. 2013;36(1):35.

15. Balen R, Rhodes C, Ward L. The power of stories: Using narrative for interdisciplinary learning in health and social care. Soc Work Educ. 2010;29(4):416-426.

16. The Pharmaceutical Society of Ireland. Core competency framework for pharmacists. https://www.hse.ie/eng/services/list/4/ mental-health-services/advancingrecoveryireland/nationalframework-for-recovery-in-mental-health/. Accessed March 10, 2017.

17. Fink LD. Creating significant learning experiences: An Integrated Approach to Designing College Courses. $2^{\text {nd }}$ Ed. CA: John Wiley and Sons. 2013.

18. Henderson C, Noblett J, Parke H, et al. Mental health-related stigma in health care and mental health-care settings. Lancet Psychiatry. 2014;1(6):467-482.

19. O'Reilly CL, Bell JS, Kelly PJ, Chen TF. Exploring the relationship between mental health stigma, knowledge and provision of pharmacy services for consumers with schizophrenia. Res Soc Adm Pharm. 2013; 11(3):e101-e109.

20. Fung KM, Tsang HW, Corrigan PW. Self-stigma of people with schizophrenia as predictor of their adherence to psychosocial treatment. Psychiatr Rehabil J. 2008;32(2):95.

21. Fink L Dee. Creating significant Learning Experiences. An Integrated Approach to Designing College Courses. $2^{\text {nd }}$ Ed. CA: John Wiley and Sons. 2013.

22. Bonwell CC, Eison JA. Active earning: Creating Excitement in the Classroom. ASHE-ERIC Higher Education Report Number 1. Washington DC. The George Washington University, School of Edication and Human Development; 1991.

23. Tsingos C, Bosnic-Anticevich S, Smith L. Reflective practice and its implications for pharmacy education. Am J Pharm Educ. 2014;78(1): Article 18.

24. Ryan C, O'Mahony D, Kennedy J, Weedle P, Byrne S.

Potentially inappropriate prescribing in an Irish elderly population in primary care. Br J Clin Pharmacol. 2009;68(6):936-947.

25. Report of the Benzodiazepine Committee. Department of Health. https:/health.gov.ie/blog/publications/report-of-the-benzodiazepinecommittee/. Accessed March 10, 2017.

26. Meagher DP, Meisinger M, Geaney N, O’Brien S. Five year follow-up of an evidence-based prescribing intervention. The Psychiatrist. 2008;32:183-186.

27. Hynes C, Keating D, McWilliams S, et al. Glasgow antipsychotic side-effects scale for clozapine: development and validation of a clozapine-specific side-effects scale. Schizophr Res. 2015;168(1-2): 505-513.

28. Barkhof E, Meijer CJ, de Sonneville LM, Linszen DH, de Haan L. Interventions to improve adherence to antipsychotic medication in patients with schizophrenia-a review of the past decade. Eur Psychiatry. 2012;27(1):9-18.

29. Julius RJ, Novitsky Jr MA, Dubin WR. Medication adherence: a review of the literature and implications for clinical practice.

J Psychiatr Pract. 2009;15(1):34-44.
30. Finley PR, Crismon ML, Rush AJ. Evaluating the impact of pharmacists in mental health: a systematic review. Pharmacotherapy. 2003;23(12):1634-1644.

31. Bell S, McLachlan AJ, Aslani P, Whitehead P, Chen TF. Community pharmacy services to optimise the use of medications for mental illness: a systematic review. Aust New Zealand Health Policy. 2005;2(1):1.

32. Crump K, Boo G, Liew FS, et al. New Zealand community pharmacists' views of their roles in meeting medicine-related needs for people with mental illness. Research in social and administrative pharmacy. 2011;7(2):122-133.

33. Bell JS, Rosen A, Aslani P, Whitehead P, Chen TF. Developing the role of pharmacists as members of community mental health teams: perspectives of pharmacists and mental health professionals. Res Soc Adm Pharm. 2007;3(4):392-409.

34. Wheeler A, Mey A, Kelly F, Hattingh L, K. Davey A. Education and training for community pharmacists in mental health practice: how to equip this workforce for the future. Journal of Mental Health Training, Education and Practice. 2014;9(3):133-144.

35. Report of the Expert Group on Mental Health Policy. A Vision for Change. Department of Health. Ireland. http://www.hse.ie/eng/ services/publications/Mentalhealth/Mental_Health_-_A_Vision_ for_Change.pdf. Accessed April 24, 2017.

36. Thornicroft G, Mehta N, Clement S, et al. Evidence for effective interventions to reduce mental-health-related stigma and discrimination. Lancet. 2016;387(10023):1123-1132.

37. Slade M. Personal Recovery and Mental Illness: a Guide for Mental Health Professionals. Cambridge: Cambridge University Press; 2009.

38. The UK ECT Review Group. Efficacy and safety of electroconvulsive therapy in depressive disorders: a systematic review and meta-analysis. Lancet. 2003;361(9360):799-808. 39. Dowman J, Patel A, Rajput K. Electroconvulsive therapy: attitudes and misconceptions. $J$ ECT. 2005;21(2):84-87.

40. Repper J, Perkins R. Recovery and social inclusion. In P. Callaghan, J. Playle \& L. Cooper (Eds), Mental Health Nursing Skills. Recovery and Social Inclusion. Oxford: Oxford University Press. 2009:85-95.

41. Deegan PE. Recovery and empowerment for people with psychiatric disabilities. Soc Work Health Care. 1997;25(3):11-24. 42. Commission for Healthcare Audit and Inspection. The pathway to recovery. A review of acute inpatient mental health services. https://www.ucl.ac.uk/core-resource-pack/resources/papers/ healthcare_commission_2008_The_pathway_to_recovery. pdf Accessed April 24, 2017.

43. Royal Pharmaceutical Society. Medicines optimisation: Helping patients to make the most of medicines. https:/www.rpharms.com/ Portals/0/RPS\%20document\%201ibrary/Open\%20access/Policy/ helping-patients-make-the-most-of-their-medicines.pdf. Accessed April 24, 2017.

44. McGuire JM, Bynum LA, Wright E. The effect of an elective psychiatry course on pharmacy student empathy. Curr Pharm Teach Learn. 2016;8(4):565-571.

45. Rickles NM, Dube GL, McCarter A, Olshan JS. Relationship between attitudes toward mental illness and provision of pharmacy services. J Am Pharm Assoc. 2010;50(6):704-713.

46. O'Reilly CL, Bell JS, Chen TF. Consumer-led mental health education for pharmacy students. Am J Pharm Educ. 2010;74(9): Article 167.

47. O'Reilly CL, Bell JS, Kelly PJ, Chen TF. Impact of mental health first aid training on pharmacy students' knowledge, attitudes and 


\section{American Journal of Pharmaceutical Education 2019; 83 (5) Article 6784.}

self-reported behaviour: a controlled trial. Aust $N$ Z J Psychiatry. 2011;45(7):549-557.

48. Dipaula BA, Qian J, Mehdizadegan N, Simoni-Wastila L. An elective psychiatric course to reduce pharmacy students' social distance toward people with severe mental illness. Am J Pharm Educ. 2011;75(4). Article 72.

49. Goldstone LW, Cooley J. An interprofessional psychiatric advanced pharmacy practice experience. Am J Pharm Educ. 2013; 77(6):Article 129.
50. Einat $\mathrm{H}$, George A. Positive attitude change toward psychiatry in pharmacy students following an active learning psychopharmacology course. Acad Psychiatry. 2008;32(6):515-517.

51. McCann E, Higgins A, Maguire G, et al. A survey of pedagogical approaches and quality mechanisms used in education programs for mental health professionals. J Interprof Care. 2012;26(5):383-389.

52. Lysaker PH, Buck KD, Lintner JI. Addressing recovery from severe mental illness in clinical supervision of advanced students. J Psychosoc Nurse Ment Health Serv. 2009;47(4):36-42. 


\section{American Journal of Pharmaceutical Education 2019; 83 (5) Article 6784.}

\section{Appendix 1. Extracts From Student Reflections}

1. "The main thing for me personally was that any apprehension I previously had about the hospital dissipated quite quickly once I entered and listened to the staff speak about it" (Reflection 20).

2. "I had a preconceived idea of what I thought it was going to be like and fortunately it wasn't like this...I thought the site visit was particularly helpful as it meant you got to voice your own opinion but also explore where you got this opinion from" (Reflection 11).

3. "Before visiting the hospital I was quite overwhelmed at the idea of caring for someone with mental health issues" (Reflection 1).

4. "I already has previous experience with mentally ill patients and have quite a good understanding of many of the conditions and how it affects patient's lives. I always had the view that mental illness should be treated in a caring and respectful manner. This view has not changed as such but rather reinforced during my visit to the hospital" (Reflection 28).

5. "As a pharmacist we must develop open, professional relationships with patients, their families and caregivers and other members of the healthcare team" (Reflection 13)

6. "The site visit changed my perceptions about working in mental health care as I was unaware of the extent of interdisciplinary work towards recovery and wellness of patients" (Reflection 16).

7. "As a pharmacist we mostly deal with patients who have been diagnosed. Pharmacists may counsel newly diagnosed patients on their medicines but rarely do we consider the journey the patient has been on from symptoms to diagnosis, that takes place outside of the doctor's office" (Reflection 5).

8. "I found the session with the psychologist very interesting and unique. It helped to put us in the perspective of the patient in the form of group therapy. It allowed me to visualise the experience a patient might have in this setting and its importance for them as therapy" (Reflection 12).

9. "I am not sure why, but I was quite surprised in a way that ECT was offered in the hospital. Having had an honest and informative explanation as to why this therapy is used I think it is likely that I had pre-formed stereotypes about this therapy" (Reflection 28).

10. "It encouraged us to discuss side effects of antidepressants and antipsychotics with patients, to treat mental health patients the same as any other patients and to not be afraid of them" (Reflection 6).

11. "My role is not only to ensure the safe use of medicines for these patients but also to be an understanding and empathetic person with whom they can speak if they need to" (Reflection 24).

12. "Something as simple as asking a person how they are getting on with their medication could make all the difference" (Reflection 27).

13. "We learned how multidisciplinary the mental health service is. . Recovery is not just about medication" (Reflection 6).

14. "I also realised how central patients are in their own care. I would have thought that patients had less involvement in their own treatment in psychiatric hospitals than they do. However, there is such an emphasis in involving the patient as in this way they become actively involved in their own recovery" (Reflection 14). 